\title{
Proteomic Approach to the Study of Statin Pleiotropy in Kidney Transplant Patients
}

\author{
Vanessa Pérez $^{a} \quad$ Maribel Navarro-Muñoz $^{a}$ Sebastián Mas ${ }^{d}$ Beatriz Bayés $^{a}$ \\ Mari Cruz Pastor ${ }^{b}$ Eva Martínez-Cáceres ${ }^{c}$ Ricardo Lauzurica ${ }^{a} \quad J^{\prime}$ Jús Egido ${ }^{d}$ \\ Ramón Romero ${ }^{a}$ \\ Departments of a Nephrology and ${ }^{b}$ Clinical Biochemistry, Germans Trias i Pujol University Hospital, and \\ 'Laboratory of Immunobiology for Research and Diagnosis - Blood and Tissue Bank (LIRAD-BST), Germans Trias i \\ Pujol Research Institute, Autonomous University of Barcelona, Barcelona, and d Laboratory of Vascular Pathology \\ and Experimental Nephrology, Fundación Jiménez Díaz, Autonomous University of Madrid, Madrid, Spain
}

\section{Key Words}

Statins $\cdot$ Kidney transplantation $\cdot$ Proteomics $\cdot$ Magnetic

beads $\cdot$ Matrix-assisted laser desorption/ionization

time-of-flight • Bradykinin • Complement factor C4

\begin{abstract}
Background/Aims: Statins are prescribed in kidney transplant recipients in order to manage dyslipidemia, a common complication in these patients. The efficacy of statins in reducing cholesterol levels has been accompanied by pleiotropic effects. Fifty-four kidney transplant patients were included in the present study, the objective of which was to ascertain the effect of 12 weeks of atorvastatin therapy (10 $\mathrm{mg} /$ day) on the patients' lipid profile, renal function, markers of inflammation and plasma peptide profile. Methods: Biochemical variables were determined with a routine clinical laboratory analyzer, and the proteomic approach was based on magnetic particle-assisted sample processing coupled to mass spectrometry readout. Results: Atorvastatin therapy improved the lipid profile of patients and caused significant changes in their plasma peptide profile; peptides with $\mathrm{m} / \mathrm{z}$ 1063 and 1898 decreased after treatment and were identi-
\end{abstract}

fied as fragments derived from molecules involved in vascular inflammation, i.e. high-molecular-weight kininogen and complement factor C4, respectively. Conclusion: These findings may contribute to the growing body of evidence of the anti-inflammatory actions attributed to statins, by which these drugs could improve these patients' clinical status.

Copyright $\odot 2011$ S. Karger AG, Basel

\section{Introduction}

Dyslipidemia is a common complication in kidney transplant recipients, playing a major role in the development of atherosclerosis and cardiovascular disease, currently the leading causes of morbidity and mortality in this population [1]. Statins are the first-line agents used to prevent and control lipid disorders in the after transplantation. They reduce the incidence of cardiovascular events [2,3] and inhibit cholesterol biosynthesis by selectively and competitively inhibiting the 3-hydroxy-3methylglutaryl coenzyme A (HMG-CoA) reductase enzyme which catalyzes the conversion of HMG-CoA to mevalonate, the rate-limiting step in de novo cholesterol

\section{KARGER}

Fax +41613061234 E-Mail karger@karger.ch www.karger.com
(C) 2011 S. Karger AG, Basel

0031-7012/11/0874-0161\$38.00/0

Accessible online at:

www.karger.com/pha
Dr. Ramón Romero González

Department of Nephrology, Germans Trias i Pujol University Hospital

Autonomous University of Barcelona, Carretera del Canyet

ES-08916 Badalona (Spain)

Tel. +34934978 898, E-Mail rromero.germanstrias@gencat.cat 
synthesis [4]. The clinical benefits of statins have mainly been ascribed to this ability $[5,6]$. However, there is a growing body of evidence suggesting that some of the effects of statins are due to lipid-independent or pleiotropic mechanisms, which may be explained by inhibition of the synthesis of nonsteroidal isoprenoid compounds produced from mevalonic acid. These pleiotropic mechanisms include anti-inflammatory, antithrombotic and plaque-stabilizing effects [7-9]. Unraveling pathways and mechanisms altered by these drugs may be beneficial for its use in clinical practice.

Human blood contains a complex array of peptides, most of them fragments of larger proteins that have been proteolytically degraded, which constitute the plasma peptidome [10], whose study by proteomic techniques may provide valuable information about biological events occurring in the organism, considering that proteins, rather than genes, are responsible for a great part of these events. Proteomics is, therefore, a suitable and powerful technique for the study of changes in the peptide profile of biological fluids caused, for example, by a therapeutic intervention.

Several works have used proteomic techniques aiming to clarify the pleiotropic effects of statins [11-14], including mass spectrometry (MS) analyses, whose advances allow the simultaneous measurement of thousands of peptides with only a small amount of sample. Most of these works have used two-dimensional electrophoresis for the fractionation of the proteome, which is a laborious and time-consuming technique. In this study, we used a technology that enabled us to analyze a considerable number of samples rapidly and in an automatable way, and more importantly, with high sensitivity and reproducibility. Peptides were captured and concentrated using superparamagnetic microparticles with a dedicated functional surface, automated with a liquid-handling robot, and followed by matrix-assisted laser desorption/ ionization time-of-flight (MALDI-TOF) MS and tandem MS. This proteomic approach has been successfully standardized in other studies to profile the peptidome of different biological fluids [15-20].

Aiming to clarify the mechanisms involved in the pleiotropy of statins, the objectives of the present study were (1) to test the effect of atorvastatin therapy on lipid profile, renal function and markers of inflammation - ultrasensitive C-reactive protein (CRP) and tumor necrosis factor- $\alpha$ (TNF- $\alpha$ ) - of kidney transplant patients and (2) to ascertain, by proteomics, whether this therapy modified the patients' plasma peptide profile.

\section{Patients and Methods}

Patients and Study Protocol

This prospective study included 54 kidney transplant patients ( 24 women; mean age: $46 \pm 13$ years) with hypercholesterolemia, stable renal function and more than 1 year of functioning graft. Eighty-five percent of patients had hypertension, $26 \%$ were obese (body mass index $\geq 30$ ), and 35\% were smokers. Immunosuppressive therapy during the study period consisted of prednisone $65 \%$, cyclosporine $78 \%$, tacrolimus $19 \%$, mycophenolate mofetil $35 \%$, and azathioprine $4 \%$. No patient received renin-angiotensin system blockers. This medication was not modified throughout the study period.

Atorvastatin (10 mg/day) was administered to all patients. Blood and urine samples were obtained at baseline and after 12 weeks of atorvastatin therapy in order to determine the trend of lipid profile, renal function, markers of inflammation, and plasma peptide profile.

The study protocol was approved by the local Ethics Committee and all patients gave their informed consent to participate in the study.

\section{Biochemical Analyses}

Biochemical variables were determined with a routine clinical chemistry laboratory analyzer immediately after extraction. Total cholesterol (TC), triglycerides (TGs), high-density lipoprotein cholesterol (HDL-C), and creatinine concentration were determined by conventional enzymatic methods whereas low-density lipoprotein cholesterol (LDL-C) was calculated according to the Friedewald equation [21]. The atherogenic index was calculated as the ratio of plasma levels of TC to plasma levels of HDL-C [22]. Serum levels of apolipoprotein (Apo) A, Apo B, and CRP were measured using a BN ProSpec nephelometer (Dade Behring $\mathrm{GmbH}$, Marburg, Germany). Serum TNF- $\alpha$ level was determined by a chemiluminescent enzyme-labeled immunoassay with an Immulite analyzer (DPC, Los Angeles, Calif., USA).

\section{Sample Fractionation}

Handling of every blood sample after collection in EDTA-prepared tubes was uniform. Plasma was obtained by centrifugation of blood samples at 2,200 $\mathrm{g}$ for $10 \mathrm{~min}$, aliquoted, and frozen at $-80^{\circ} \mathrm{C}$ until further usage.

For peptide fraction isolation, frozen plasma aliquots were thawed at room temperature and processed immediately. The profiling kit used was the MB-IMAC Cu (Bruker Daltonics, Bremen, Germany), which is based on the affinity of peptides for immobilized copper ions on the surface of the magnetic beads. Washing, binding and elution procedures were conducted, making a duplicate for each sample, in 96-well polypropylene plates (NUNC, Thermo Fisher Scientific, Roskilde, Denmark) as recommended by the manufacturer, except where modified for optimization purposes. Briefly, the magnetic beads were mixed thoroughly by vortexing for 2 min to obtain a homogeneous dispersion, $5 \mu \mathrm{l}$ were deposited in the plate and washed 3 times with 50 $\mu l$ of the binding buffer provided in the kit. After each washing step, the plate was placed on a magnetic separator allowing particles to be retained and removing the supernatant. Eighty microliters of plasma were added to the wells containing the prewashed beads and left for $5 \mathrm{~min}$ at room temperature to allow the specific binding of the peptides to the surface of the beads. Beads 
were washed 3 times with $100 \mu$ l of washing buffer to remove the unbound molecules and undesirable components. The bound peptides were eluted from the magnetic beads with $15 \mu \mathrm{l}$ of elution buffer. The eluted fraction was diluted 1:5 with LC-grade water (Lab-Scan, Gliwice, Poland), and then mixed 1:2 with UVabsorbing matrix solution $(1.84 \mathrm{mg} / \mathrm{ml} \mathrm{2,6-dihidroxyacetophe-}$ none, $20 \%$ acetonitrile (ACN), $40 \mathrm{mmol} / \mathrm{l}$ ammonium citrate dibasic). One microliter of the resulting mixture was deposited in duplicate onto a MALDI target plate (AnchorChip 600/384, Bruker Daltonics) and allowed to air-dry at room temperature to let the matrix crystallize. In this manner, 8 spots of each patient were analyzed, half of the baseline and half of the posttherapy state.

All samples were processed automatically (i.e. peptide fraction isolation, addition of matrix and deposition on the MALDI target plate) with a liquid-handling robot (Freedom Evo, Tecan, Männedorf, Switzerland), which improved throughput and ensured reproducibility.

\section{Mass Spectrometry}

MALDI-TOF MS analyses were performed in an UltraFlex II TOF instrument (Bruker Daltonics). Ionization was achieved by irradiation with a 337-nm nitrogen laser operating in positive linear mode with a repetition rate of $20 \mathrm{~Hz}$. All spectra were collected by summing 300 laser shots, delivered in three sets of 100 shots at different positions on the spot surface, with ion source voltages of 20 and $17.35 \mathrm{kV}$; reflector $1,21.08 \mathrm{kV}$; reflector 2, 11.85 $\mathrm{kV}$; time delay, $300 \mathrm{~ns}$ and laser energy, $70 \%$. An external mass calibration was performed using commercially available calibration standards (ClinProt Peptide Calibration Standard I, Bruker Daltonics), obtaining a mass accuracy $<40 \mathrm{ppm}$. All peaks with a signal-to-noise ratio $>3$ in the low-mass range (1-4 kDa) were recorded with the FlexControl acquisition software (version 2.0, Bruker Daltonics).

\section{Data Analysis}

Four spectra of each sample were obtained, and a detailed analysis was performed using DataAnalysis software (version 3.4, Bruker Daltonics), seeking to choose the best spectrum for each patient at a determined state. Spectra with the highest number of peaks and the highest intensity were selected. ClinProTools software (version 2.0, Bruker Daltonics) was used for the recalibration of the selected spectra, normalizing them to their total ion count and calculating their peak area. For statistical operations, spectral data were converted to ASCII files, exported to Excel spreadsheets and finally analyzed with SPSS software (version 15.0, SPSS Inc., Chicago, Ill., USA).

\section{Nano-LC-MALDI-TOF/TOF MS}

Peptides were spotted directly onto a MALDI target, and analyzed by MALDI-TOF/TOF MS as follows. Eluates were trapped and desalted in a C18 trap column (Ziptip, Millipore, Bedford, Mass., USA). Peptides were eluted onto a 576-spot MALDI plate (Applied Biosystems, Foster City, Calif., USA) using a $3 \mathrm{mg} / \mathrm{ml} \alpha$ cyano-4-hydroxy cinnamic acid (Sigma-Aldrich, Milwaukee, Wisc., USA) in 50\% ACN and $0.1 \%$ trifluoroacetic acid.

MS analyses were performed automatically with a 4700 MALDI-TOF/TOF analyzer (Applied Biosystems). First, MS spectra of all the spotted fractions were acquired in positive reflector mode for peak selection. Up to 8 of the most intense ions per spot with S/N450 were selected as precursors for MS/MS ac- quisition excluding common trypsin autolysis peaks for peptides from the membrane fraction. Up to 6 of the most intense ions per spot with S/N460 were selected as precursors for MS/MS. The search for filtered peptides was performed using GPS Explorer v3.5 software (Applied Biosystems) with a licensed version 1.9 of MASCOT (Matrix Science, London, UK).

The MASCOT search parameters were: (1) species: mammalia (NCBInr); (2) allowed number of missed cleavages: 1; (3) variable modifications: methionine oxidation; (4) peptide tolerance: \pm 150 ppm; (5) MS/MS tolerance: $\pm 0.35 \mathrm{Da}$ and (6): peptide charge: \pm 1 . Only proteins identified with a score confidence interval $\% \geq 95$ were accepted. This parameter is provided by GPS-Explorer software and is based on the MASCOT score.

\section{Validation of Proteomic Results by Alternative Techniques}

Nephelometry

Plasma samples of 8 kidney transplant patients (6 women; mean age: $48 \pm 14$ years), at baseline and after 12 weeks of statin therapy, were used to measure the plasma concentration of complement factor C4 with a BN II nephelometer (Dade Behring).

\section{Enzyme Immunoassay}

Bradykinin was measured in plasma samples of 16 kidney transplant patients (10 men; mean age: $48 \pm 13$ years), obtained at baseline and after 12 weeks of statin therapy, using a competitive bradykinin enzyme immunoassay kit (Phoenix Europe $\mathrm{GmbH}$, Karlsruhe, Germany) with a minimum detectable concentration of $0.09 \mathrm{ng} / \mathrm{ml}$ and a range from 0 to $100 \mathrm{ng} / \mathrm{ml}$. Fractionation of samples with magnetic beads MB-IMAC Cu (Bruker Daltonics) was conducted, as described previously, using $80 \mu \mathrm{l}$ of plasma. The eluent of the resulting peptide fraction was dried in a Speed Vac concentrator (Savant Instruments Inc., Farmingdale, N.Y., USA) and stored at $-20^{\circ} \mathrm{C}$ until further assay. Peptide fractions were diluted 1:25 to fall the values within the stated range of detection. The measurement of bradykinin was performed according to the procedure provided by the manufacturer. Each sample was analyzed in duplicate and absorbance optical density values were fluorometrically read at $450 \mathrm{~nm}$ on a Varioskan Flash spectral scanning reader (Thermo Fisher Scientific, Vantaa, Finland). The measured concentrations were assessed with the SkanIt Software for Varioskan Flash (version 2.4.1) by extrapolation from a standard curve constructed using samples containing defined quantities of bradykinin.

Statistical Analysis

Normality was established using the Kolmogorov-Smirnov test. For normally distributed variables, the results are expressed as means \pm standard deviations and for nonnormally distributed variables, as the median (interquartile ranges). Student's t test for paired samples or the nonparametric Wilcoxon test were performed as required to determine whether plasma peptide profile or analytical variables after statin therapy differed from the baseline. Associations among variables were estimated using Spearman correlations. Differences in plasma peptide profile according to gender, age and immunosuppression were calculated with the nonparametric Mann-Whitney $U$ test. All analyses were performed using SPSS software (version. 15.0). A p value $<0.05$ was considered significant. 


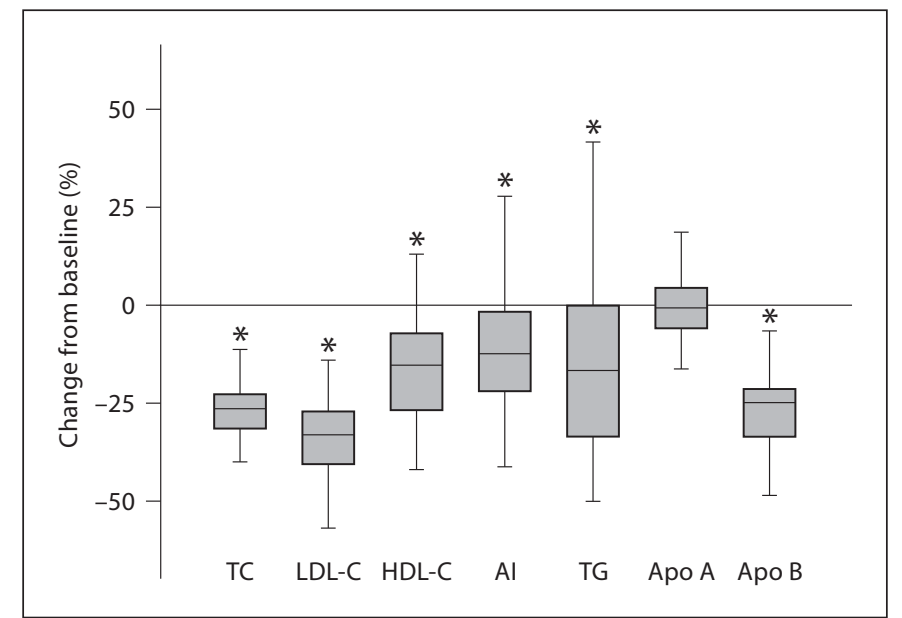

Fig. 1. Percentage change of lipid and apolipoprotein profile of kidney transplant patients after 12 weeks of atorvastatin therapy. $\mathrm{AI}=$ Atherogenic index. The Wilcoxon test was performed to assess differences between lipid and apolipoprotein profile at baseline and after atorvastatin therapy. ${ }^{*} \mathrm{p}<0.005$.

\section{Results}

\section{Effect of Atorvastatin Therapy on Biochemical}

Parameters

The biochemical characteristics (lipid profile, renal function parameters and markers of inflammation) of kidney transplant patients, at baseline and after 12 weeks of atorvastatin therapy, are presented in table 1.

Statin therapy significantly improved the lipid profile of kidney transplant patients, with a median reduction in TC of $-26.32 \%$ ( -31.32 to $-22.62 \%)$, in LDL-C of $-33.55 \%$ ( -40.53 to $-27.26 \%)$, in TGs of $-16.67 \%$ ( -33.33 to $3.57 \%$ ), and in Apo B of $-26.56 \%$ (-33.52 to $-21.44 \%)$ (fig. 1). The atherogenic index also decreased $-12.46 \%(-22.21$ to $0.44 \%)$. After treatment, 75.93 and $79.25 \%$ of the patients achieved TC and LDL-C concentrations within the reference range below 5.2 and $3.3 \mathrm{mmol} / \mathrm{l}$, respectively. Furthermore, half of the patients showed a reduction in LDLC concentrations below $2.59 \mathrm{mmol} / \mathrm{l}$ after treatment, as recommended by the guidelines for managing dyslipidemia in kidney transplant patients [23]. The decrease in TC and LDL-C was negatively correlated with the patients' age $(\mathrm{r}=-0.418, \mathrm{p}=0.002 ; \mathrm{r}=-0.304, \mathrm{p}=0.028$, respectively) and showed no association with gender.

Renal function remained stable, without significant changes in creatinine clearance and proteinuria.

After statin therapy, the markers of inflammation CRP and TNF- $\alpha$ showed a median decrease of $-30.58 \%$
Table 1. Biochemical characteristics of kidney transplant patients before and after 12 weeks of atorvastatin therapy

\begin{tabular}{lccc}
\hline & Baseline & 12 weeks & $\mathrm{p}$ \\
\hline TC, mmol/l & $6.49 \pm 1.16$ & $4.76 \pm 0.81$ & $<0.001$ \\
LDL-C, mmol/l & $4.10 \pm 0.88$ & $2.72 \pm 0.63$ & $<0.001$ \\
HDL-C, mmol/l & $1.65 \pm 0.48$ & $1.38 \pm 0.39$ & $<0.001$ \\
Atherogenic index & $4.16 \pm 1.04$ & $3.63 \pm 0.88$ & $<0.001$ \\
TGs, mmol/l & $1.63 \pm 0.68$ & $1.40 \pm 0.65$ & $<0.001$ \\
Apo A, g/l & $1.68 \pm 0.33$ & $1.66 \pm 0.30$ & 0.464 \\
Apo B, g/l & $1.23 \pm 0.22$ & $0.90 \pm 0.17$ & $<0.001$ \\
Creatinine clear- & & & \\
$\quad$ ance, ml/min & $61.34 \pm 28.37$ & $58.76 \pm 25.69$ & 0.328 \\
Proteinuria, g/24 h & $0.21(0.11-0.46)$ & $0.21(0.15-0.56)$ & 0.278 \\
CRP, mg/l & $2.00(0.74-5.90)$ & $1.53(0.61-3.80)$ & 0.522 \\
TNF- $\alpha, \mathrm{pg} / \mathrm{ml}$ & $6.70(4.90-7.90)$ & $5.90(5.13-7.58)$ & 0.278
\end{tabular}

Data are shown as means $\pm \mathrm{SD}$ or as medians (interquartile ranges in parentheses) depending on variable normality.

To assess differences, Student's t test for paired samples or the nonparametric Wilcoxon test was performed as required.

A p value $<0.05$ was considered significant.

( -53.81 to $41.09 \%)$ and $-2.38 \%$ ( -14.55 to $24.72 \%)$, respectively, although it was not statistically significant. Using the logarithmic transformation of TNF- $\alpha$ and CRP values to decrease their skewness and normalize them, no significant differences in TNF- $\alpha$ levels were found, but in the case of CRP, a tendency to decrease after therapy ( $p=0.081)$ was observed. Although no significant correlation was found between changes in CRP levels and changes in HDL-C $(r=-0.009, \mathrm{p}=0.956)$ or TG $(r=0.284, p=0.080)$, the correlation with LDL-C was significant $(\mathrm{r}=0.331, \mathrm{p}=0.043)$. The changes in TNF- $\alpha$ did not correlate with changes in the lipid profile. Taking into account the levels of CRP and TNF- $\alpha$ at baseline, we used their median value as the cut-off for grouping patients; as a result, no significant changes after treatment were observed in these markers in patients with high or low levels at baseline.

Fifty-six percent of the patients had CRP levels of $3 \mathrm{mg} / \mathrm{l}$ or above at baseline, which are considered to confer a high risk of cardiovascular disease; after statin therapy $42 \%$ of these patients achieved levels of CRP below $3 \mathrm{mg} / \mathrm{l}$. When comparing changes in markers of inflammation between smokers and nonsmokers, and between obese (BMI >30) and nonobese patients, no differences were found. 
Table 2. Peak area of plasma peptides before and after 12 weeks of atorvastatin therapy

\begin{tabular}{lccr}
\hline Peptide $(\mathrm{m} / \mathrm{z})$ & Baseline, AU & 12 weeks, AU & $\mathrm{p}$ \\
\hline 1553 & $3.15(2.08-5.79)$ & $8.67(2.99-24.60)$ & $<0.001$ \\
2008 & $19.44(10.96-31.09)$ & $34.62(14.37-98.42)$ & 0.008 \\
2085 & $33.93(25.23-61.86)$ & $63.96(41.70-108.65)$ & $<0.001$ \\
1049 & $36.27(21.28-64.58)$ & $31.05(13.02-40.38)$ & 0.029 \\
1063 & $670.08(323.22-1,102.90)$ & $385.60(204.04-545.41)$ & $<0.001$ \\
1079 & $180.03(70.58-439.06)$ & $127.24(45.86-210.08)$ & $<0.001$ \\
1532 & $31.05(10.96-73.34)$ & $11.87(7.69-32.25)$ & 0.002 \\
1741 & $21.25(10.28-33.15)$ & $12.11(7.65-22.64)$ & 0.011 \\
1898 & $356.16(215.35-573.97)$ & $286.91(119.85-438.10)$ & 0.035 \\
2312 & $128.14(52.76-238.71)$ & $67.17(29.18-99.00)$ & $<0.001$ \\
2375 & $55.79(32.99-81.51)$ & $42.63(25.52-57.96)$ & 0.006 \\
2486 & $196.78(67.69-328.46)$ & $104.95(38.90-170.74)$ & 0.001 \\
2661 & $24.68(16.15-38.66)$ & $14.62(9.93-21.97)$ & $<0.001$ \\
2864 & $116.88(76.35-171.59)$ & $50.11(30.41-86.42)$ & $<0.001$ \\
\hline
\end{tabular}

Peptides with m/z 1553, 2008 and 2085 increased, whereas the remaining peptides decreased after statin therapy. Data are expressed, in arbitrary units (AU), as median (interquartile ranges). The nonparametric Wilcoxon test was performed to assess differences. A p value $<0.05$ was considered significant.

\section{Effect of Atorvastatin Therapy on Plasma Peptide}

Profile

Statistically significant changes in plasma peptide profile of kidney transplant patients were found after atorvastatin therapy. Considering the peptide signals in which there was a change after therapy, we observed that in 3 of them there was an increase in intensity - mass-tocharge $(\mathrm{m} / \mathrm{z}) 1553,2008$ and 2085 - and in 11 there was a decrease (m/z 1049, 1063, 1079, 1532, 1741, 1898, 2312, 2375, 2486, 2661 and 2864) (table 2).

Peptide m/z 1063 was identified as a fragment derived from the protein high-molecular-weight kininogen (HMWK) (SwissProt accession No.: P01042; Homo sapiens). Within this protein, the amino acid sequence identified is RPPGFSPFR (381-389) that corresponds to the nonapeptide bradykinin. A significant decrease in its peak area of $-46.21 \%$ (-69.59 to $33.14 \%$ ) was observed after atorvastatin therapy (fig. 2a).

Peptide $\mathrm{m} / \mathrm{z} 1898$ was identified as a fragment derived from the protein complement factor C4 (SwissProt accession No.: P0C0L4; Homo sapiens; amino acid sequence 1337-1352). After atorvastatin therapy, a decrease in its peak area of $-31.82 \%$ ( -58.61 to $32.29 \%)$ was observed (fig. 2b).

A positive correlation was observed between reductions in TC, LDL-C and Apo B levels and the decrease in the peak area of the peptide $\mathrm{m} / \mathrm{z} 1898(\mathrm{r}=0.375, \mathrm{p}=0.005$; $\mathrm{r}=0.376, \mathrm{p}=0.006 ; \mathrm{r}=0.278, \mathrm{p}=0.046$, respectively). On the contrary, there was no correlation between changes in the peptide $\mathrm{m} / \mathrm{z} 1063$ and changes in the lipid profile. Moreover, changes in peptides m/z 1063 and 1898 were independent of changes in renal function parameters, markers of inflammation and immunosuppression taken during the study period.

Validation of the peptide bradykinin by enzyme immunoassay showed that, after statin therapy, there was a reduction in the plasma concentration of this peptide in $61 \%$ of the patients analyzed (fig. 2c).

The validation of complement factor $\mathrm{C} 4$ by nephelometry showed that, after statin therapy, there was a reduction in this protein in $75 \%$ of the patients analyzed (fig. 2d).

\section{Discussion}

Here we used a nonbiased approach for the search of peptides/proteins differentially expressed in kidney transplant patients in response to atorvastatin therapy, in an attempt to understand the pathways affected by the so-called pleiotropic effects of statins.

As expected, because statins reduce endogenous cholesterol synthesis, atorvastatin therapy resulted in an improvement in the patients' lipid profile. Moreover, statins are also believed to have clinical benefits greater than what would be expected only from the cholesterol-lower- 


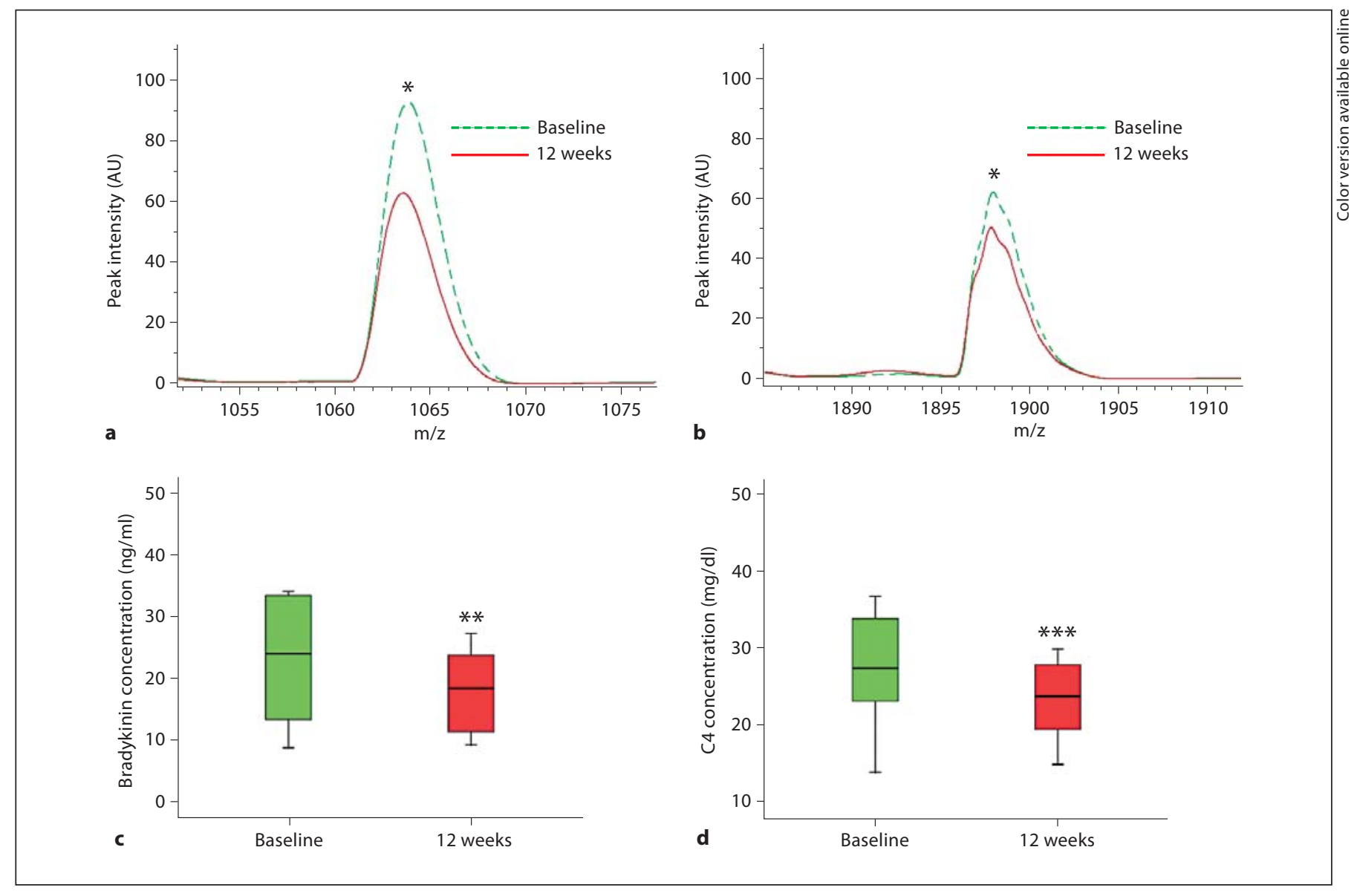

Fig. 2. a, b Average intensity, in arbitrary units (AU), for peptide signals m/z 1063 and 1898, respectively, of 54 kidney transplant patients at baseline and after 12 weeks of atorvastatin treatment. c Plasma concentration of bradykinin in 16 kidney transplant patients measured by enzyme immunoassay. d Plasma concentra-

tion of complement factor $\mathrm{C} 4$ in 8 kidney transplant patients measured by nephelometry. The Wilcoxon test was performed to assess differences between patients at baseline and after 3 months of therapy with atorvastatin. ${ }^{*} \mathrm{p}<0.005 ;{ }^{* *} \mathrm{p}=0.100 ;{ }^{* * *} \mathrm{p}=$ 0.050 .

ing effect, including renoprotective and anti-inflammatory effects.

With respect to renal function, the effect of statins is a controversial issue. While several studies have suggested that statins have renoprotective effects, even in kidney transplant patients, other studies, as the present one, have not found this effect or have even reported a detrimental effect [24-29].

Statins have also been suggested to reduce inflammation, an important issue since inflammation plays a major role in the pathogenesis of atherosclerosis [30,31]. Our study did not show a reduction in markers of inflammation due to statin therapy; anti-inflammatory actions of statins may depend on the dose administered, and most studies reported in this regard were designed with higher

doses of statins or over a longer period of time [32-35]. A recent study stated that the anti-inflammatory actions of statins are limited to patients whose markers of inflammation are elevated at baseline, but we could not draw the same conclusion based on our results [36].

MS has been previously used in order to shed light on the molecular mechanisms of statin therapy in humans [11-14]. These studies have provided information about the possible pleiotropic effects but, to our knowledge, this is the first time that the effect of a statin is studied on the peptide profile of plasma from kidney transplant patients. Our approach was based on a combination of magnetic bead technology with MS, which allows studying a considerable quantity of peptides/proteins contained in a small blood sample. 
The intensity of two peaks, identified as peptides belonging to proteins involved in the inflammatory process, was reduced after statin therapy. Tubes containing EDTA were used for blood collection; this anticoagulant inhibits the coagulation pathway but does not prevent the activation of factor XII, that auto-activates by contact with negatively charged surfaces, activating kallikrein, which, in turn, liberates bradykinin from HMWK. Factor XII also activates the classic complement system. Therefore, bradykinin and peptides of the complement factor $\mathrm{C} 4$ are generated by proteolytic events occurring at the initiation of the ex vivo blood clotting and complement activation cascades, respectively. Nevertheless, and because all samples were processed in the same way, the differences observed in the intensity of these peptides after statin therapy may reflect the amount of the nonhydrolyzed parent proteins in blood.

The hormone bradykinin is one of the most important inflammatory mediators; it has vasodilator and hypotensive effects by stimulation of release of nitric oxide, prostaglandin $\mathrm{I}_{2}$, smooth muscle hyperpolarization factor and superoxide. Bradykinin also increases capillar permeability and induces edema. Statin therapy improves endothelial function and possibly causes kinin generation at the endothelial surface, but the association between these drugs and the circulating kallikrein-kinin system has not been widely studied. A publication in type 2-diabetic patients found no differences in circulating bradykinin and other peptides and proteins of the kallikrein-kinin system following statin therapy [37] whereas our results suggest that statins may improve the patients' inflammatory status via the kallikrein-kinin system. Note that no patients of this study received angiotensinconverting enzyme inhibitors, which are well known to increase levels of bradykinin in blood by inhibiting its degradation [38].
Complement factor $\mathrm{C} 4$ is part of the classical pathway of complement activation and plays a key role in the removal of immune complexes, which leads to vascular inflammation and atherosclerosis. The cleavage of complement factor $\mathrm{C} 4 \alpha$-chain leads to the release of the anaphylatoxin $\mathrm{C} 4 \mathrm{a}$, a mediator of local inflammation. Serum levels of complement factor $\mathrm{C} 4$ have been described as a powerful predictor of stroke [39], and other components of the complement cascade have been demonstrated to predict vascular events, i.e. components C5a and C3 [40, 41]. Moreover, serum levels of $C 4$ have been suggested to monitor the anti-inflammatory effect of statins in patients with coronary artery disease [42].

\section{Conclusion}

Statins have been hypothesized to have pleiotropic effects, but the mechanisms involved have not been fully clarified. We attempted to determine the role of statins as lipid-lowering, anti-inflammatory and renoprotective agents in kidney transplant patients and, moreover, we analyzed the effect of these drugs on the plasma peptide profile.

The finding of a decrease in plasma of peptides belonging to molecules involved in vascular inflammation may enhance our knowledge on the anti-inflammatory mechanisms attributed to statins, by which these drugs could improve patients' clinical status.

The preliminary data of this study suggest a potential application of magnetic particle-based sample processing followed by MALDI-TOF MS readout as an effective tool for the investigation of molecular modifications in complex samples induced by a drug therapy, and may be an interesting way of studying pleiotropy or new drug targets.

\section{References}

Proteomic Approach to the Study of Statin Pleiotropy
Lindholm A, Albrechtsen D, Frodin L, Tufveson G, Persson NH, Lundgren G: Ischemic heart disease - major cause of death and graft loss after renal transplantation in Scandinavia. Transplantation 1995;60:451457.

-2 Scandinavian Group: Randomised trial of cholesterol lowering in 4444 patients with coronary heart disease: The Scandinavian Simvastatin Survival Study (4S). Lancet 1994;344:1383-1389.

-3 Holdaas H, Fellstrom B, Jardine AG, Holme I, Nyberg G, Fauchald P, Gronhagen-Riska C, Madsen S, Neumayer HH, Cole E, Maes B,
Ambuhl P, Olsson AG, Hartmann A, Solbu DO, Pedersen TR: Effect of fluvastatin on cardiac outcomes in renal transplant recipients: a multicentre, randomised, placebocontrolled trial. Lancet 2003;361:2024-2031.

4 Istvan ES, Deisenhofer J: Structural mechanism for statin inhibition of HMG-CoA reductase. Science 2001;292:1160-1164.

5 Heart Protection Study Collaborative Group: MRC/BHF heart protection study of cholesterol lowering with simvastatin in 20,536 high-risk individuals: a randomised placebo-controlled trial. Lancet 2002;360: $7-22$.

Statin Pleiotropy 
-6 Shepherd J, Cobbe SM, Ford I, Isles CG, Lorimer AR, MacFarlane PW, McKillop JH, Packard CJ: Prevention of coronary heart disease with pravastatin in men with hypercholesterolemia. West of Scotland Coronary Prevention Study Group. N Engl J Med 1995; 333:1301-1307.

7 Massy ZA, Keane WF, Kasiske BL: Inhibition of the mevalonate pathway: benefits beyond cholesterol reduction? Lancet 1996;347:102103.

8 Davignon J: Beneficial cardiovascular pleiotropic effects of statins. Circulation 2004; 109:III39-III43.

-9 Wang CY, Liu PY, Liao JK: Pleiotropic effects of statin therapy: molecular mechanisms and clinical results. Trends Mol Med 2008; 14:37-44.

-10 Richter R, Schulz-Knappe P, Schrader M, Standker L, Jurgens M, Tammen H, Forssmann WG: Composition of the peptide fraction in human blood plasma: database of circulating human peptides. J Chromatogr B Biomed Sci Appl 1999;726:25-35.

-11 Duran MC, Martin-Ventura JL, Mohammed S, Barderas MG, Blanco-Colio LM, Mas S, Moral V, Ortega L, Tunon J, Jensen ON, Vivanco F, Egido J: Atorvastatin modulates the profile of proteins released by human atherosclerotic plaques. Eur J Pharmacol 2007;562: 119-129.

12 Alonso-Orgaz S, Moreno L, Macaya C, Rico L, Mateos-Caceres PJ, Sacristan D, PerezVizcaino F, Segura A, Tamargo J, LopezFarre A: Proteomic study of plasma from moderate hypercholesterolemic patients. J Proteome Res 2006;5:2301-2308.

13 Barderas MG, Tunon J, Darde VM, De la Cuesta F, Jimenez-Nacher JJ, Tarin N, LopezBescos L, Egido J, Vivanco F: Atorvastatin modifies the protein profile of circulating human monocytes after an acute coronary syndrome. Proteomics 2009;9:1982-1993.

14 Perez V, Navarro-Munoz M, Bayes B, Lauzurica R, Pastor MC, Troya M, Bonet J, Ibernon M, Navarro M, Serra A, Nunez A, Romero R: Effect of low doses of atorvastatin on the urinary peptide profile of kidney transplant patients. Transplant Proc 2009;41:2111-2114.

15 Villanueva J, Philip J, Entenberg D, Chaparro CA, Tanwar MK, Holland EC, Tempst P: Serum peptide profiling by magnetic particle-assisted, automated sample processing and MALDI-TOF mass spectrometry. Anal Chem 2004;76:1560-1570.

- 16 Baumann S, Ceglarek U, Fiedler GM, Lembcke J, Leichtle A, Thiery J: Standardized approach to proteome profiling of human serum based on magnetic bead separation and matrix-assisted laser desorption/ ionization time-of-flight mass spectrometry. Clin Chem 2005;51:973-980.

17 West-Nielsen M, Hogdall EV, Marchiori E, Hogdall CK, Schou C, Heegaard NH: Sample handling for mass spectrometric proteomic investigations of human sera. Anal Chem 2005;77:5114-5123.

18 Fiedler GM, Baumann S, Leichtle A, Oltmann A, Kase J, Thiery J, Ceglarek U: Stan- dardized peptidome profiling of human urine by magnetic bead separation and matrix-assisted laser desorption/ionization time-of-flight mass spectrometry. Clin Chem 2007;53:421-428.

19 Callesen AK, Christensen R, Madsen JS, Vach W, Zapico E, Cold S, Jorgensen PE, Mogensen $\mathrm{O}$, Kruse TA, Jensen ON: Reproducibility of serum protein profiling by systematic assessment using solid-phase extraction and matrix-assisted laser desorption/ionization mass spectrometry. Rapid Commun Mass Spectrom 2008;22:291-300.

20 Sekiyama E MY, Higo D, Nirasawa T, Ikegawa M, et al: Applying magnetic bead separation/MALDI-TOF mass spectrometry to human tear fluid proteome analysis. J Proteomics Bioinform 2008;1:368-373.

21 Friedewald WT, Levy RI, Fredrickson DS: Estimation of the concentration of low-density lipoprotein cholesterol in plasma, without use of the preparative ultracentrifuge. Clin Chem 1972;18:499-502.

22 Castelli WP: Lipids, risk factors and ischaemic heart disease. Atherosclerosis 1996; 124(suppl):S1-S9.

23 Kasiske BL: Clinical practice guidelines for managing dyslipidemias in kidney transplant patients. Am J Transplant 2005;5:1576

24 Toso A, Maioli M, Leoncini M, Gallopin M Tedeschi D, Micheletti C, Manzone C, Amato M, Bellandi F: Usefulness of atorvastatin $(80 \mathrm{mg})$ in prevention of contrast-induced nephropathy in patients with chronic renal disease. Am J Cardiol 2010;105:288-292.

25 Masterson R, Hewitson T, Leikis M, Walker R, Cohney S, Becker G: Impact of statin treatment on 1-year functional and histologic renal allograft outcome. Transplantation 2005;80:332-338.

26 Fellström B, Abedini S, Holdaas H, Jardine AG, Staffler B, Gimpelewicz C: No detrimental effect on renal function during long-term use of fluvastatin in renal transplant recipients in the Assessment of Lescol in Renal Transplantation (ALERT) study. Clin Transplant 2006;20:732-739.

27 Fried LF, Orchard TJ, Kasiske BL: Effect of lipid reduction on the progression of renal disease: a meta-analysis. Kidney Int 2001;59: 260-269.

28 Agarwal R: Effects of statins on renal function. Am J Cardiol 2006;97:748-755.

29 Davidson MH: Rosuvastatin safety: Lessons from the FDA review and post-approval surveillance. Expert Opin Drug Saf 2004;3:547557.

-30 Albert MA, Danielson E, Rifai N, Ridker PM: Effect of statin therapy on c-reactive protein levels: The Pravastatin Inflammation/CRP Evaluation (PRINCE): a randomized trial and cohort study. JAMA 2001;286:64-70.

31 Nawawi H, Osman NS, Yusoff K, Khalid BA: Reduction in serum levels of adhesion molecules, interleukin- 6 and C-reactive protein following short-term low-dose atorvastatin treatment in patients with non-familial hypercholesterolemia. Horm Metab Res 2003; 35:479-485.
-32 van Wissen S, Trip MD, Smilde TJ, de Graaf J, Stalenhoef AF, Kastelein JJ: Differential hs-CRP reduction in patients with familial hypercholesterolemia treated with aggressive or conventional statin therapy. Atherosclerosis 2002;165:361-366.

33 Ozaki K, Kubo T, Imaki R, Shinagawa H, Fukaya $\mathrm{H}$, Ohtaki K, Ozaki S, Izumi T, Aizawa Y: The anti-atherosclerotic effects of lipid lowering with atorvastatin in patients with hypercholesterolemia. J Atheroscler Thromb 2006;13:216-219.

- 34 Singh U, Devaraj S, Jialal I, Siegel D: Comparison effect of atorvastatin (10 versus 80 $\mathrm{mg}$ ) on biomarkers of inflammation and oxidative stress in subjects with metabolic syndrome. Am J Cardiol 2008;102:321-325.

- 35 Nissen SE, Tuzcu EM, Schoenhagen P, Brown BG, Ganz P, Vogel RA, Crowe T, Howard G, Cooper CJ, Brodie B, Grines CL, DeMaria AN: Effect of intensive compared with moderate lipid-lowering therapy on progression of coronary atherosclerosis: a randomized controlled trial. JAMA 2004; 291:1071-1080.

- 36 Horiuchi Y, Hirayama S, Soda S, Seino U, Kon M, Ueno T, Idei M, Hanyu O, Tsuda T, Ohmura H, Miida T: Statin therapy reduces inflammatory markers in hypercholesterolemic patients with high baseline levels. J Atheroscler Thromb 2010;17:722-729.

37 Campbell DJ, Kladis A, Zhang Y, Jenkins AJ, Prior DL, Yii M, Kenny JF, Black MJ, Kelly DJ: Increased tissue kallikrein levels in type 2 diabetes. Diabetologia 2010;53:779-785.

38 Tschope C, Schultheiss HP, Walther T: Multiple interactions between the renin-angiotensin and the kallikrein-kinin systems: role of ACE inhibition and AT1 receptor blockade. J Cardiovasc Pharmacol 2002;39:478487.

39 Cavusoglu E, Eng C, Chopra V, Ruwende C, Yanamadala S, Clark LT, Pinsky DJ, Marmur JD: Usefulness of the serum complement component $\mathrm{C} 4$ as a predictor of stroke in patients with known or suspected coronary artery disease referred for coronary angiography. Am J Cardiol 2007;100:164-168.

40 Speidl WS, Exner M, Amighi J, Kastl SP, Zorn G, Maurer G, Wagner O, Huber K, Minar E, Wojta J, Schillinger M: Complement component $\mathrm{C} 5 \mathrm{a}$ predicts future cardiovascular events in patients with advanced atherosclerosis. Eur Heart J 2005;26:22942299.

-41 Szeplaki G, Prohaszka Z, Duba J, Rugonfalvi-Kiss S, Karadi I, Kokai M, Kramer J, Fust G, Kleiber M, Romics L, Varga L: Association of high serum concentration of the third component of complement (C3) with pre-existing severe coronary artery disease and new vascular events in women. Atherosclerosis 2004;177:383-389.

42 Sampietro T, Bigazzi F, Rossi G, Dal Pino B, Puntoni MR, Sbrana F, Chella E, Bionda A: Upregulation of the immune system in primary hypercholesterolaemia: effect of atorvastatin therapy. J Intern Med 2005;257:523530. 